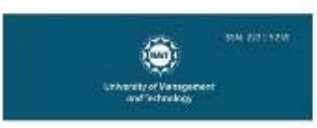

\title{
Organization Theory Review (OTR)
}

Volume No.1 Issue No. 1 Fall 2017

ISSN: 2221-2876

PTOganization

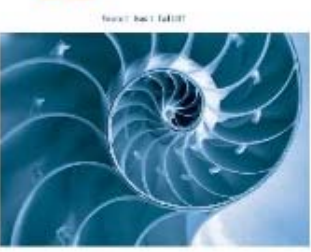

Journal DOI: https://doi.org/10.29145/otr

Issue DOI: https://doi.org/10.29145/otr/11

Homepage: https://spa.umt.edu.pk/otr/home.aspx

Journal QR Code:
Article:

Author:

Online Published:

Article DOI:

Article QR Code: Re-Thinking Neuroticism: Organizational Learning to Learning
Organization (Dynamic Capability Development)

Muhammad Rizwan Junaid

October 2017

$\underline{10.29145 / \mathrm{otr} / 11 / 010104}$

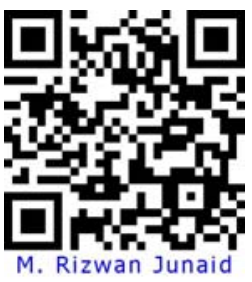

Junaid, M. R. (2017). Re-Thinking neuroticism: Organizational learning to learning organization (Dynamic Capability Development).

Organization Theory Review, 1(1), 27-40. DOI: https://doi.org/ 10.29145/otr/11/010104

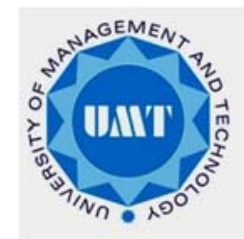

A publication of the

School of Professional Advancement

University of Management and Technology

Lahore 


\title{
Re-Thinking Neuroticism: Organizational Learning to Learning Organization (Dynamic Capability Development) Muhammad Rizwan Junaid
}

\author{
Pakistan Institute of Management, Lahore, Pakistan
}

\begin{abstract}
In many personal psychological studies, neuroticism has been taken as one of the integral elements along with other. However, we do not find any such study where neuroticism is focused in its very individual capacity as an influential mode of human attitude. The core perspective of this research initiative is to look into different objective facets of neuroticism within the close proximity of an organization that is established within a society for the sole purpose to facilitate human beings with respect to multi-dimensional needs. The theoretical framework established in the very beginning and served as a benchmark to regress all the corresponding sections to prove influence of neuroticism on human cognition that impacts individual learning cycle.
\end{abstract}

Keywords: neuroticism, cognition, learning, dynamic capability, organization development

\section{Introduction}

The role of employees is so significant in taking an organization forward from individual to learning organization. An employee is most sacred and precious resource an organization possesses and capitalizing on this resource always brings lasting sustainable competitive advantages for a commercial establishment. The entire process is not linear but circular and needed to be understood in the very right perspective of behavioral changes that an individual comes across under the influence of internal/external forces. Our aim in this paper is to review whole process of organizational transformation and look into the role of neuroticism, as discussed in details in coming paragraphs that if it is not taken seriously or if it is not understood completely then it derails the whole process of intellectual and organizational growth. The theoretical framework presented is regressed with available literature, theories and psychological contributions in order to look into the role neuroticism.

\section{Theoretical Framework}

The theoretical framework for this research initiative carries forward and further expounds the hypothesis regarding impact of neuroticism on individual learning; a very specific, significant and core phase in the whole process, which maintains the flow of knowledge dissemination by forming a consolidate body of individual learners (Mumford, 1991) within an organization. The continuous learning stages with reference to organizational knowledge (deconstruction, re-construction and coconstruction) are individually (Goldman, 2005) centered and collectively processed. The concentrated individual learning goes along with organizational learning; it requires such a nourishing, interactive and positive environment that not only gets every individual member under its fold but also stimulates its members towards selfmotivated learning.

The self-motivated learning enables members of an organization to gain dynamic capabilities that ensures a full fledge learning organization with sustainable competitive advantage. At this juncture, role of neuroticism seems prominently significant; it is the core of this study to look into the role of neurotic behaviors, especially of managers, that influence the process of dynamic capabilities development in an organization. The cyclic process of organizational learning depends upon the role played by neurotic behaviors; as if it is obstructing then the continuous improvement cannot be guaranteed and vice versa. 


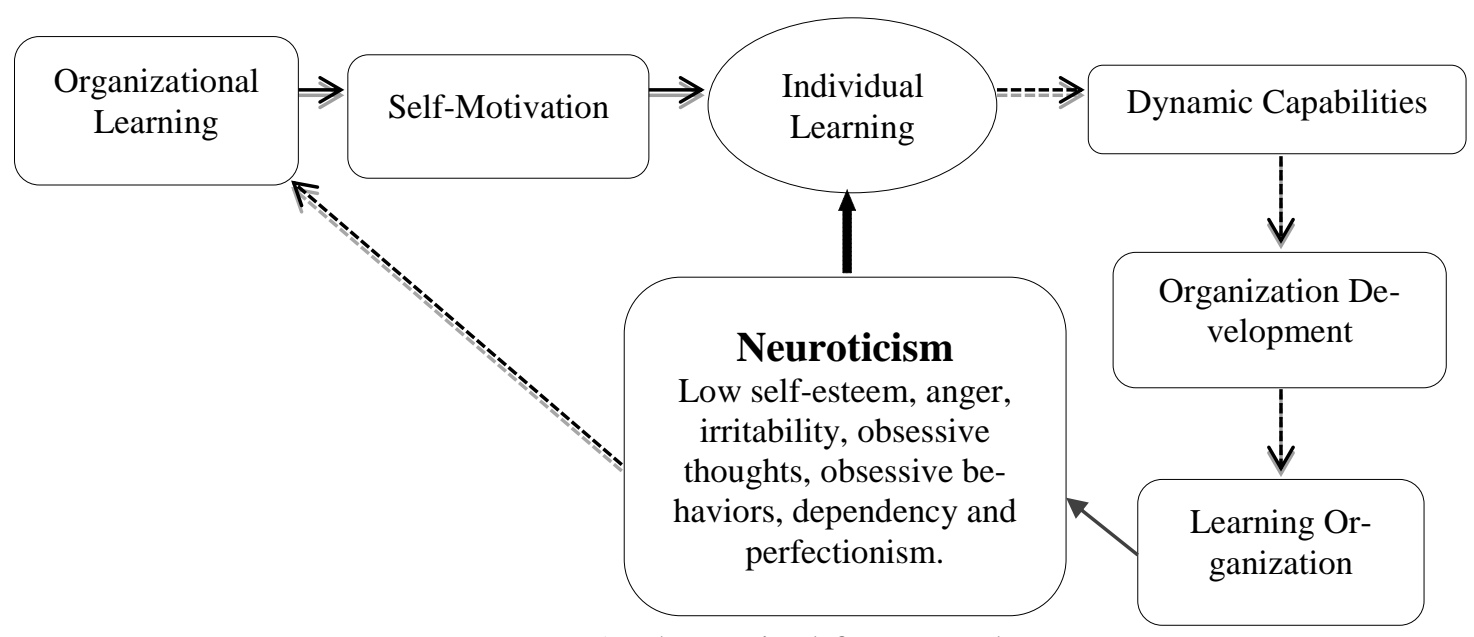

Figure 1. Theoretical framework

\section{Organizational Learning}

Organization theory is primarily a complex discipline that studies behaviors of commercial/non-commercial organizations and their closely knitted relationship with the overall environment in which they basically function (Daft, 2009). The conceptual scope of organization theory encircles organization psychology, human resource development, organizational systems, strategic management, leadership and organization learning etc. (Morgan, 1996). Among all the captioned areas under the realm of organization theory, the significance of organizational learning seems paramount and considerable as it directly relates with behavioristic patterns within an organization. Argyris and Schon (1978) manifested organizational learning as an effect/product of organization inquiry; they described that in case of not achieving the desired or planned outcome, individual or a group from within the organization involve themselves in an inquiry in order to comprehend the causes and reason behind. These individuals develop interaction with other members of organization and this interaction paves the way towards collective learning, learning can be considered as the direct outcome of this interaction.

The learning model presented by Daniel (1993) is a comprehensive integration of different models, his model analyzes the break down in organizational systems that occur due to a dead lock between individu- al's input referencing any particular problem and failure in organizational acceptance. This deadlock seems problematic for individual as well as for organization. Nonaka and Takeuchi (1995) addressed this issue through presenting a multi-dimensional model incorporating knowledge creation and organization learning in an infinite spiral of socialization, internalization, externalization and combination. Watson (2002) somewhat, came up with altogether a different approach as he emphasized upon lack of research in organization learning and emphasized that the traceable path of organization learning initiated through individual learning and connectionism provides a transitional framework that presented a model seems capable to incorporate tacit and explicit modes of learning and knowledge. Bontis and Serenko (2009) linked the process of organization learning with effective human capital management, their study highlighted the significance of employee emotion and knowledge management. They focused the notion of individual's involvement in organization learning process and made it clear that individual learning and organization learning must move hand in hand.

Bushe (2009) clarified that through organization learning discussions, individuals come across their own experience and experience of others which paves the way for them to review and revise their very own pattern of learning (Bushe, 2009) and come 
up with an improved version of their personal experiences. Employees validate their learning with organization learning and this intellectual comparative combination leaves them with a balanced relationship that lasts longer on positive grounds.

\section{Individual Learning}

Learning has been defined as the activity or process of gaining knowledge or skill by studying, practicing, being taught, or experiencing something (Webster, 2000). Learning is examplified as

"The process of acquiring a modification in a behavioral tendency by experience (as exposure to conditioning) in contrast to modifications occurring because of development or a temporary physiological condition (as fatigue) of the organism; also: the modified behavioral tendency itself" (Webster, 2000).

There are number of other definitions available but our core intention is to comprehend the concept of learning in the very right perspective of Psychology and Physiology as well. Our interest is to look into behavioral modifications in an individual in relation with the environment in which one performs number of activities being a very part of it and even excel through personal development.

Individual learning is in fact a prerequisite for organizational learning and it is fundamentally a foundation for continuous learning within an organization. In fact, it seems all absurd and ambiguous to spell that an organization learns. Whenever we say that, we sum up the learning of scores of individualism an organization and the summation of their learning is called organizational learning (Garvin, 1993). The conceptual twist tells a different tale; as in individual learning, the notion of interaction is missing while organizational learning is based upon notion of interaction among number of individuals, groups, tiers and levels,

The fundamental essence of individual learning in an organization is based upon involvement of an individual in the exercise of augmenting functions through enhanced awareness and knowledge (Antonacopoulou, 2006 ). The foremost step to be taken by an organization in order to develop a fit for organizational learning is to create an environment where individuals are motivated to learn through their experiences, interaction and social connections (Aksu, 2005). The individual learning within an organization generates individual knowledge that eventually builds a foundation of knowledge within an organization. This process of knowledge building forms a net of organizational learning.

The intrinsic aim of this mutual learning exercise is to develop core competencies that ensure sustainable competitive advantage for an organization. The process of developing core competencies primarily starts with individual learning (Valerie \& London, 2006) that turns out in favor of organization and maintains a net of organizational learning. It is for sure that organization remains in need to establish an environment that motivates learning and knowledge sharing in a holistic manner. In fact, organizational learning is another facet of individual learning as it can be possible for an organization to learn independently of any particular individual (Kim, 1993) but it cannot be the case when we talk of the whole population of an organization. Individual learning eventually paves the way for organizational learning.

\subsection{Theories in Individual Learning}

There are many theories that encompass the process of how an individual learns, we incorporate here some of those; in order to build a conceptual support regarding those aspects that are commonly considered in individual learning: 


\subsection{Theory of Experiential Learning}

Kolb (1984) presented the theory of experiential learning, as he was of the view that human can learn faster through experience. His cyclic theory is based upon four stages which combine experience, perception, cognition and behavior. He took forward the concept initially established by Dewey (1938) that

"The creation of knowledge is through transformation of experience whereby learning is an ongoing process".

His four approaches; two (initial) to grasp experience as concrete experience and abstract conceptualization are mingled with the other two (final) to transform experience as reflective observation and active experimentation; completes the cyclic process of an individual's learning.

\subsection{Honey and Mumford's Model}

This model was a fair adaptation from Kolb's learning cycle as they divided managerial learning styles with respect to the personality profiles of different managers in four categories as activist, reflector, theorist and pragmatist and explained (Honey, 2006) further that adaptations are brought within these styles rather than in overall learning atmosphere. They developed a comprehensive questionnaire ( 80 items version) to incorporate all the above four learning styles.

\subsection{Barbe, Swassing, and Milone Learning Modalities}

Barbe et al. (1979) presented three core learning modalities as: visualizing, auditory and tactile; named them as styles. They divided learners in three different styles as above and expounded that anyone who falls in relative styles learns in a manner different from another one and we cannot generalize the process of learning for all individuals as the learning ability differs from person to person.

\subsection{Theory of Competence}

Burch (1970) presented four stages of learning any new skill; it was an evolutionary model that subjected the process of learning in it's purely a natural form. It manifested that learning process within an individual starts with an abstraction as initially any individual seems unaware of what he/she knows; they are totally unconscious of their incompetence, since that, they are unconscious of their incompetence so they acquire certain skill to overcome this incompetence and they further implement this skill consciously. The conscious use of skill and its results further stimulate an individual to go on and after acquiring every new skill and usage; the faculty of unconscious competence appears stronger within an individual.

\subsection{Howard Gardener Theory of Mul- tiple Intelligence}

Gardener (1989) developed a typology regarding notion of individual intelligence and he proposed that every individual has a unique intelligence blend and there are number of distinct forms of intelligence that are possessed by every individual. He was of the candid opinion that we must focus upon the kind of intelligence a person possesses and then we plan for his learning modules; as if an individual is good at music then we need to focus upon his building this very ability as he can excel better than those who do not possess this ability, rather as a strength.

\subsection{Leon Fistenger Cognitive Disso- nance Theory}

Festinger (1957) was of the opinion that every individual seems capable enough to maintain a consistency between his beliefs and opinions (cognition); and whenever there is an imbalance or inconsistency between attitudes or behaviors, something is needed to be done to eliminate the dissonance and every such occasion adds new behavioral knowledge in an indivudal's prevailing knowledge profiles. The 


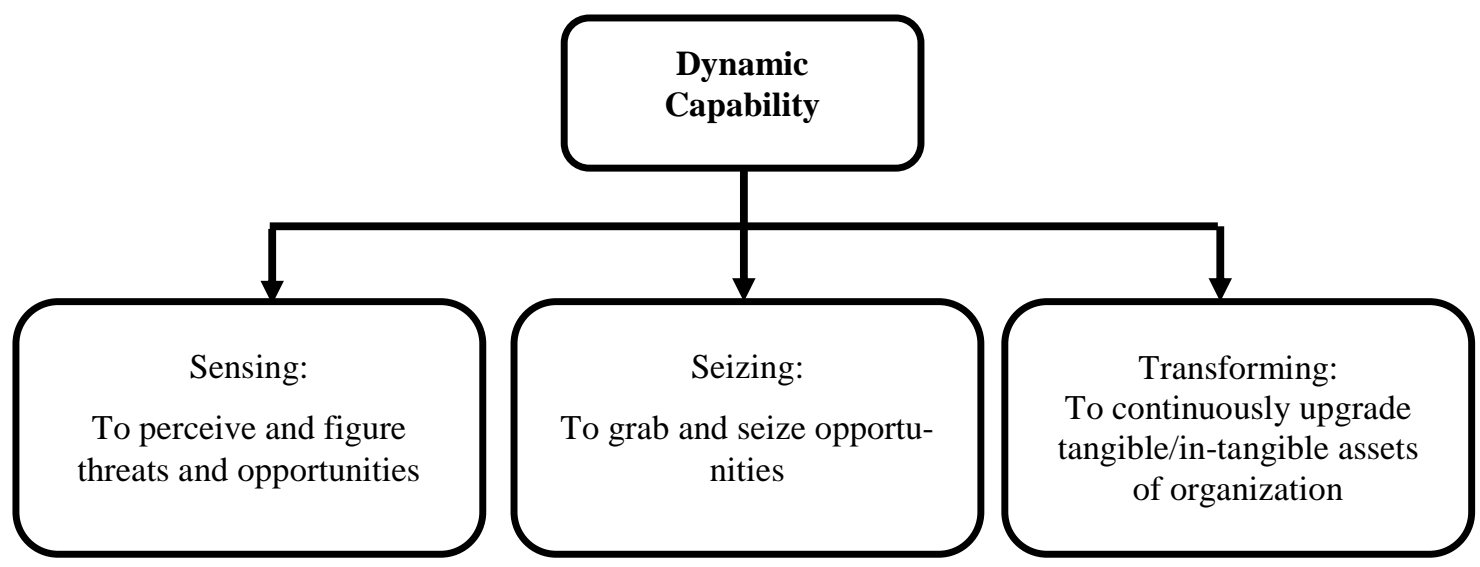

Figure 2. Teece's trio

corresponding change in attitudes and behaviors is the focal point of this theory, as attitudes always come forward to accommodate the behavior.

Self-motivation is a force that stems us to move ahead; it further inspires uninterrupted learning and accomplishment in any circumstances. Self-regulated learning comprises of many distinctive features and characteristics (Zimmerman, 1990) that enable learner to comprehend the process flow of learning and set the pace by him. Selfmotivated learning develops a sense of self efficacy (Zimmerman, 1995) that works far beyond mere concept of cognitive comprehension and behavioral modifications. In fact, the pace and process of organizational learning directly link with self-motivated learning that is the fulcrum of knowledge transformation within an organization. Selfmanaged individual and teams are highly required for smooth flow of knowledge (Belasen, 1999). The key aspect of organizational learning is the interaction that takes place at different levels and once the process begins, this interaction purely becomes a matter of self-initiation and self-discipline that is an outcome of organizational learning.

The composure, personality profile and respective role of top management play significant part in harnessing self-motivated learning across organizations; supportive leaders is one of the four pillars of organizational learning process (Hamilton \& Scandura, 2003). The prime need is to raise a culture of continuous improvement that prices organizational learning; cultural reinforcements can be witnessed (Gupta \& McDaniel, 2002) through motivating learners and evaluating results of learning for future planning and control of learning methodologies in organization. It is for sure that without linking the self motivated culture of knowledge sharing with incentives and it is where most of the organizations fail to maintain a balance between what is being done and what is to be done.

Employees (human beings) can be preemptive and involved rather they can even be isolated and alienated (Ryan \& Deci, 2000) but it depends upon the social atmosphere they are living in, the role of organization culture, especially with reference to knowledge sharing and learning is fundamental in order to take everyone on board. The focal assumption of andragogy encircling adult learner is one who keeps an independent self concept that directs his/her own learning initiatives (Merriam, 2002) and overall environment provides support and cover so that this self learning process may take place in an ideal atmosphere.

The concept of lifelong learning given by Watkins and Marsick (1993) in fact en- 
compasses quest of knowledge on voluntary, continuous and self-motivated grounds. It further exemplifies that an adult learner keeps on learning for whole of his life time and we cannot bound learning with any specific place, program or surrounding as it purely relates with human involvement and compassion. Knowledge workers, round the globe, trade knowledge and they think to live (Davenport, 2005). Their tasks seem a bit different from other employees as most of the time; they are involved in problem solving and decision making and they are more exposed to multi-dimensional thinking (Reinhardt et al., 2011). If they are not provided with a well knitted culture where knowledge generation, retention and dissemination is facilitated then their performance would not be at par. They need to be motivated up to the extent that they can turn into a self-motivator for themselves as their assignments are smart not hard (Mcdermott, 2005).

Teece and Pisano (1994) came with a novel concept titled "Dynamic Capabilities" of an organization; they established a sharp distinction between ordinary capabilities and dynamic capabilities. Ordinary capabilities are the ones that initiated by one/two organizations and they spread across whole industry while the dynamic capabilities are unique, peculiar and eccentric to an organization and they actually root in company's history. It is a set of an (David \& Teece, 1997) organization's capacity to assimilate, construct and constitute internal/external competencies to accommodate itself successfully in promptly changing corporate environment.

The fundamental crux of dynamic capability framework is Human; as humans are the only resource in an organization that ensures sustainable competitive advantage and there is no fear of imitation or copying. It is again advantageous that this resource keeps on improving, growing and changing and the sole constant feature of this very resource is change. The prime focus of an organization's culture is about getting people on board to perform without having being corrupted or forced (Teece, 2007).

It is a vital shift from resource based view of the firm to the dynamic capability view of the firm; the resource based view of the firm focuses upon sustainable competitive advantage while the dynamic capability view encircles competitive survival. In fact the high paced market conditions force a firm to come up above average and in this power play, the resources available with a company (Ludwig, 2011) are to be utilized in an interchangeable manner, as per requirement and human resources is the only resource that can be placed on multi-tasking in order to remain competitive in survival mode. Sharpening the inner capabilities of every employee and to maintain a persistent balance across whole organization is needed to produce a particular outcome on permanent basis.

Organization wide learning enables every employee to focus upon his/her own set of abilities and to use them at designated work place to gain desired outcome. The integration of individual outcome in an accumulated manner to ensure organizational outcome is the core task of dynamic capability theory where human plays the role of value based propositions. The dynamic capability theory works through process of change and the mechanism of organizational learning attaches an individual's learning in an organization with learning by organization. Knowledge generation and dissemination are undertaken consistently (Antonacopoul et al., 2005) to ensure a plausible balance between an employee's intellectual upbringing with that of an organization.

In addition to it, internal organizaitonal practices that are outcomes of a learning culture (which values knowledge and learning as assets) can be a key competency for organizational performance and competitivenes (Nonaka, 2001). The dynamic capabilities as presented by Teece are nothing but prompt renewal of internal 
capabilities to respond to external market capabilities (Eisenhardt, 2000). This notion of change is well addressed through approach towards identifying problems and fixing them in order to retain organizational

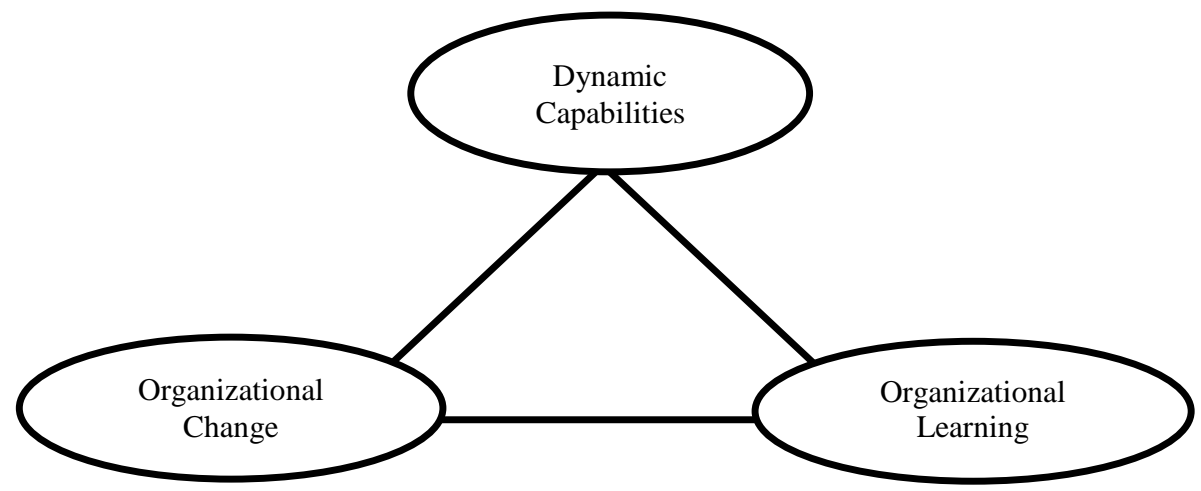

Figure 3. Triangular relationship encompasing dynamic capabilities, organizational learning, and organizational change

dynamic capabilities view, only if they have been well blended with learning culture within an organization and it furhter provides a triangular view encompassing dynamic capabilities, organizational learning and organizational change (Suchman, 2000) to re-formalize the enactment of an organization in prevailing markets. Organization Development is a definite outcome of above captioned triangle; and even another aspect of organizational learning as it is fundamentally a well-designed, methodical learning and development approach with strong intentions to bring change in beliefs and value structure of an organization; so that, an organization would turn out to be in a better position to perform consistently inrapidly changing market conditions, technological advancements and obsolesce and be adaptive for better and persistent outcomes. The process of organization development is systematic and consistent employing active organizational change in a holistic manner.

Dante and Chialvo's (2004) recent research has gone a step further and highlights many social, natural and neural systems that interact with entire organizational systems to ensure development in all spheres. Managing notion of change within organization development is basically (Brown, 2011) an efficiency and growth.

Organization development considers learning as the core characteristic of an organization with adaptive behavior (Popper, 2001) an organization with adaptive behavior learns from its surroundings (environment, internal/external). The cyclic learning process is to learn from experience and then apply back the feedback of experience (Gherardi, 2000) to attain the organization renewal stage as captioned in dynamic capability theory. It is to be kept in mind that organization development is not about training and development of staff, team building or something else like this; but the prime aim of organization development is to develop whole organization (Lester, 2002) keeping, processes, systems and structures under one fold.

Self-motivated organizational learning that develops dynamic capabilities paves the way towards sustainable organization development. Employees invest their knowledge in new experiences and they keep on learning, the intellectual growth of an employee ensures organizational development. The immediate, sustainable and comprehensive improvements in processes, systems and structures are most conducive to learning as learning and structural configuration move together. 
Once an organization passes through certain phases of internal and external development based upon learning and experiences exhibited by its members, it enters the final phase where it is named as Learning Organization where every member of the organization is continuously involved in learning and where learning and working go simultaneously and flawlessly interweaved (Pedler, 1997). The process of organizational transformation moves along and enables an organization to work upon its weaknesses and convert them back into strength. A consolidate learning organization is the one which searches for its own future where learning is encouraged for all the members and the working approach is that learning is an on-going and creative process; and it fairly cultivates adapts and transmutes itself to address need of internal and external environment (Johnson, 1993).

Learning organization sets everyone free from conventional authoritarian working paradigm and lead employees into a more open, passive and compatible environment where everyone learns by contributing (Rheem, 1995); the close net of heirarchy is trashed and duly replaced by employees' potential. The potential that encourages people to learn by learning with others and harness a sense of sense making towards objectivity and focussed orientation.

Senge (1990) in his famous work The Fifth Discipline: The Art and Practice of the Learning Organization explained five core principles that must be comprehended while introducing learning in an organization as:

In brief, learning organization shouldered off the concept that only top and senior managers can act as thinkers for entire firm. It invites all of its employees to come forward and work on their inner selves to explore novel opportunities and based upon their very own resources, they strive to perform better for the firm and remain intact with a self-motivated sense.

Any employee in an organization contributes well physically or intellectually; all learning theories and management models advocate importance of an individual; that is the reason that all core schools of philosophy encircle individualism as one of the most regarded areas under constant discussion. Learning as discussed above is an ongoing and continuous process that keeps trailing almost all the times. Organizational learning and individual learning take place simultaneously; organizations cannot learn but do facilitate the process of individual learning. This facilitation gives way to an overall culture of 'learning through sharing' with emphasis upon 'connections rather than collections'.

Organization culture, values, traits, functions, operations and processes etc. are again individuals and exist through individuals. It is evident that all employees in their very individual capacity remain in the organization with reference to their related groups (functional/ operational) and their existence goes along with their groups. Managers, senior managers and top managers exist in their very individual capacity as they represent a group (department/section); even their spectrum of influence on individual employees is very noteworthy that evenly impacts the learning process within an individual and between two individuals in an organization.

We have discussed the theoretical framework with reference to captioned stages and now, our sole aim is to look into the role of neuroticism as played/displayed by certain power quarters in an organization and its overall impact on learning process. Our sole aim is to move further with respect to neurotic personalities at managerial cadre and the role, influence and impact of this very personal trait (neuroticism) on different phases of individual and organizational learning.

\subsection{Neuroticism and Learning}

The person with neurotic symptoms or tendency towards neuroticism is more apprehensive, unpredictable and disposed to unhappiness (Howard, 1998); a person, high 
on neurotic scale seem depressed, anxious, angry with low emotional stability. It is to be clarified that neuroticism is not a psychiatric defect rather a personal state identifying a person with reference to specific category (McCrae, 1992).

Neuroticism is trademarked by dearth of attentiveness, fear of disaster and being under immense stress. In addition to it, another facet of being high neurotic is lacking critical ability and difficulty in establishing the way things related to one another (Schouwenburg, 1995). A direct link can easily be established with surface learning style (Entwistle, 1988). This style divulge a learner more in memorizing rather than concept building etc. The notion of objectivity seems stronger in these sort of learners as they are up to pass the examination, their motivation is extrinsic and overall learning approach is syllabus based-cum-objective (Entwistle, 1996).

Motamedi (2006) highlighted seven neurotic styles of management that influence workplace functions and operations, especially when we relate them to the notion of learning across organization, as any eurotic style specifies a person's inadequacy in learning desirable skills to accomodate and survive effectually in societal and work settings (Shapiro, 1989). Such a style repeatedly depicts an incapability for self actualization, motivation towards learning and developing and fetching in more actual behaviors.

Serious problems, conflicts, hook-ups and differences appear in the work place and it seems difficult perhaps even improbable to maintan a learning culture across organization and to keep every one on board. The more these styles get strengthened, the less probabiltiy of change remains within an organization, rather it is killing for inter group relationships and inter departmental problem solving and decision making drills. The generalized impact of these styles is detrimental to any organization and the pace of organization development cannot be maintained; the notion of self motivated learning turns into a full of fear saga and junior/bottom line employees try not to take initiatives or employ courage to test new ideas in order to learn by doing or discussing.

Table 1

Personality Styles by Motamedi (2006)

\section{Personality Styles}

\begin{tabular}{ll}
\hline Explosive & $\begin{array}{l}\text { Moody, emotional, dominated } \\
\text { by immediate frustration, } \\
\text { cannot rationalize }\end{array}$
\end{tabular}

Implosive Irrational thinking, personal grudges, surprise reactions, instable personality

$\begin{array}{ll}\text { Abrasive } & \begin{array}{l}\text { Dominated by perfection and } \\ \text { diligence, generate feeling of } \\ \text { inadequacy in others }\end{array}\end{array}$

Narcissist Feel high of themselves and look down upon others, self fulfilment

Apprehensive Self protective, low trust in others, skeptics, defensives, untrusting

Compulsive Inflexible mindset, keen to basic details, neglects value added dimensions

Impulsive Unplanned, un-anticipated, creates disruptions and misperceptions

All the above styles influence organizational functions and operations at individual and group level. The progress and growth factors in an organization go together and with the progression of organization, the growth of an employee seems viable. The overall attitude of an employee and senior management does count a lot, as in some of the cases people with neurotic tendencies harm themselves but often they are in the driving seat and impact a lot of others with their neurotically tainted persona. 


\section{Discussion}

Knowledge based view of the firm has made it very clear that sustainable competitive advantage is humans and their capabilities; human capabilities are the only resource that keep on upgrading themselves and they are difficult to imitate and socially complex in their very nature (Alavi \& Leidner, 2001). These capabilities are integral part of man's personality and strongly influenced by environment, surroundings, people, social role, self concept and others; some of these factors are internal and some are external, the internal factors are motivated or accelerated by external factors in shaping, up-bringing human capabilities (Funder, 2001). Besides abilities, human personality is a compact set of certain traits, The trait theory emphasizes upon studying human personality and its corresponding traits with respect to behavior, emotions and thoughts (Kassin, 2003).

There are infinite number of potential characteristcs (traits) that can be used to define human personality (Eysenck, 1991) but there is a common set of traits, rather most found and number of personal psychologists agree upon these, that introversion \& extroversion are the traits that establish fundamental dimensions of human personality (Block, 1995); and these two are closely followed by neuroticism as third core factor (Lynam, 2005). The above three core factors (introversion, extraversion, neuroticism) are further categorized according to their significance and extent, major taxonomies agree that extraversion is societal and positive while neuroticism and introversion are emotionaly instable and negative (Matthews, 2003).

Neuroticism refers to an individual's ability to turn out to be distressed or sentimental and a key factor while studying personal pathology (Jan, 2006; Takano, 2007; Deckersbach, 2006). Neuroticism is considered as the fundamental personality trait characterized by anxiety, jealousy, depression, anger and guilt etc. (Thompson, 2008). The impact of introversion and extraversion is all the way different from that of neuroticism; as the influence of former two have nothing to do with evolutionary abilities of a human being as they are static, uniform, constant and nonaggrevated. The case of neuroticism is different as it directly impacts the cognitive ability of an individual.

Learning, Cognition refers (Sternberg, 2009) to mental activities (perception, memory, reasoning and judgement); cognitive processes circle around receiving, transmitting and operating information (Blomberg, 2011).

Being introvert/extrovert are permanent states of a personality, if a person is introvert by nature and if it is a fundamental characteristic of one's personality then it remains static, permanent, uniform, unchanged, rigid and lasting. On the other hand, neuroticism, as explained earlier is an evolutionary characteristic of human personality and it is multi-dimensional, temporal, reactionary, aggravated and complex in nature and most of the time; it impacts the cognitive process within a human being. The process of learning is a life time, cyclic pro-

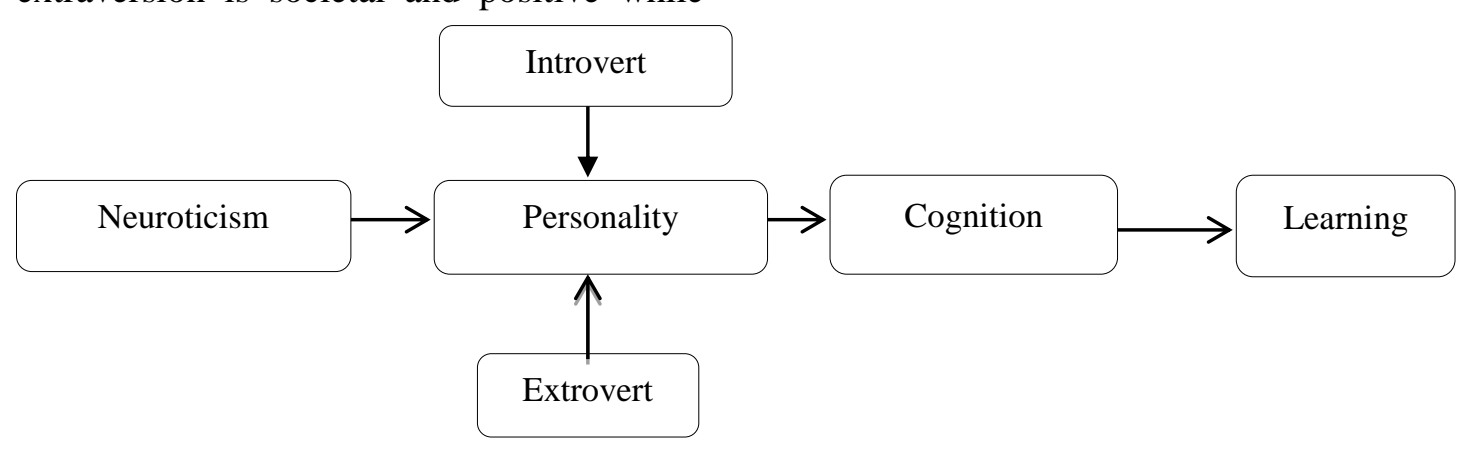

Figure 5. Cognitive learning cycle

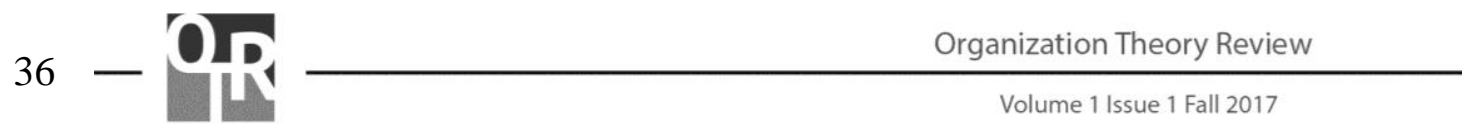


cess that keeps going on across whole life of an individual; being neurotic is very damaging for learning as it does not leave a person composed enough to be ready to learn new things or be a part of learning atmosphere.

Initially emotions were not listed as part of cognition but recent researches in psychology have manifested that emotions are even an active part of meta cognition (Matlin, 2009) as the state of high/low emotions highly influence the learning paradigm. If a person is emotionally instable (as emotional instability) is one of the core neurotic traits then it seems difficult perhaps even improbable for him/her to remain in a balance cognitive mode. External factors do affect cognitions people have and emotions they maintain (McGlone, 2007) and their communication patterns, tone and style expose these effects as depicted through interactions. The interaction between emotion and cognition is more complex than it was believed and emotional variations encircle the thinking ability of a person (Greengrass, 2002) and it seems visible once certain tasks are given to such a person who goes overwhelmed beneath torrent of emotions.

William Cullen who coined the term Neurosis in $17^{\text {th }}$ century, explained neurosis as "sensual and kinetic disorder" (Spitzer \& Williams, 1980); further considered as nonphysical mental illness that triggers an emotional imbalance within a human and this imbalance does not leave an individual composed enough to go for any analytical, mental and cognitive endeavour (Russon, 2003). Cognitive process directly interacts with emotional phenomena of an individual and they jointly play pivotal role in depression, anxiety, personality and relevant psychological disorders (Robinson et al., 2013). It is evident that we cannot draw a straight line separating cognition and emotion. Neuroticism is a measure of affect and emotional control; low level of neuroticism ensures emotional stability while high level manifests the possibility of being negatively emotional most of the time (Howard, 1995).

\section{Conclusion}

Based on the discussion above, we hypothersized in our theoretical framework that Neuroticism influences the learning abilitiy of an individual that eventually hampers organizational learning that is undertaken to gain dynamic capabilities. If neurotic behaviors are not well incorporated in individual learning processes then we would not be able to frame or form a learning organization. The influence of neuroticism is two fold as (1) putting a neurotic individual in an organization to learn and share his experiences and (2) placing a neurotic individual in driving seat where he can affect the learning initiatives of other individuals within an organization. There is much to be done in this area of personal psychology and this manuscript is just an intial efforts towards opening a way for comprehensive, research based discussions from experts and practitioners.

\section{References}

Aksu, A. A., \& Özdemir, B. (2005). Individual learning and organization culture in learning organizations: Five star hotels in Antalya region of Turkey. Managerial Auditing Journal, 20(4), 422-441.

Alavi, M., \& Leidner, D. E. (2001). Knowledge management and knowledge management systems: Conceptual foundations and research issues. MIS Quarterly, 25(1), 107-136.

Antonacopoulou, E. P. (2006). The relationship between individual and organizational learning: New evidence from managerial learning practices. Management Learning, 37(4), 455-473.

Antonacopoulou, Elena., Ferdinand, Jason, Graca, Manuel., Easterby, M.S. (2005). Dynamic capabilities and organizational learning: A socio political tension in organizational renewal (Advanced Institute of Management Research Paper 
No. 14). Retrieved from https://papers.ssrn.com/sol3/papers.cfm?a bstract_id $=1306958$

Aksu, A. A., \& Özdemir, B. (2005). Individual learning and organization culture in learning organizations: Five star hotels in Antalya region of Turkey. Managerial Auditing Journal, 20(4), 422-441.

Argyris, C., \& Schön, D. (1978). Organizational Learning: A theory of action perspective. Reis: Revista Española de Investigaciones Sociológicas, 77/78, 345-348.

Barbe, W. B., Milone, M. N., \& Swassing, R. H. (1979). Teaching through modality strengths: Concepts and practices. Zaner-Bloser.

Belasen, A. T. (1999). Leading the learning organization: Communication and competencies for managing change (SUNY series: Human Communication Processes). Albany: State University of New York Press.

Block, J. (1995). A contrarian view of the five-factor approach to personality description. Psychological Bulletin, 117, 187-215.

Blomberg, O. (2011). Concepts of cognition for cognitive engineering. International Journal of Aviation Psychology 21(1), 85-104.

Bontis, N., \& Serenko, A. (2009). A causal model of human capital antecedents and consequents in the financial services industry. Journal of Intellectual Capital, 10(1), 53-89.

Brown, D. H. (2011). An experiential approach to organization development. New Jersey, USA: Pearson Education.

Burch, N. (1970). Theory of competence. California: Gordon Training International.

Bushe, G. (2009). Learning from collective experience: A different view of organizational learning. Organization Development Practitioner, 41(3), 19-23.

Daft, R. A. (2009). Organization theory and design. Toronto: Nelson.
Dante, R., \& Chialvo, M. K. (2004). Organization, development and function of complex brain networks. Trends in Cognitive Science, 8(9), 418-425.

Davenport, T. H. (2005). Thinking for a living: How to get better performance and results from knowledge workers. Boston: Harvard Business School Press.

David, J., \& Teece, G. P. (1997). Dynamic capabilities and strategic management. Strategic Management Journal, 18(7), 509-533.

Deckersbach, T. E. A. (2006). Regional cerebral brain metabolism correlates of neuroticism and extraversion. Depress Anxiety. 23(3), 133-8.

Dewey, J. (1938). Expereicne and education. London: Collier Books.

Eisenhardt, K. M. (2000). Dynamic capabilities, what are they? Strategic Management Journal, 21, 1105-1121.

Entwistle, N. (1996). Approaches and study skills inventory for students. Edinburgh: Centre for Research on Learning and Instruction, University of Edinburgh.

Entwistle, N. (1988). Motivational factors in students' approaches to learning. In R. P. Schmeck (Ed.). Learning strategies and learning styles. New York: Plenum Press.

Eysenck, H. (1991). Dimensions of personality: 16: 5 or 3? Criteria for a taxonomic paradigm. Personality and Individual Differences, 12, 773-790.

Festinger, L. (1957). A theory of cognitive dissonance. Stanford, CA: Stanford University Press.

Funder, D. (2001). Personality. Annual. Review of Psychology, 52, 197-221.

Gardner, H. (1989). Multiple intelligences go to school: Educational implications of the theory of multiple intelligences. Educational Researcher, 18(8), 4-10.

Garvin, D. A. (1993). Building a learning organization. Massachusetts: Harvard Business Review.

Gherardi, S. (2000). Practice-based theorizing on learning and knowing in organizations. Organization, 7(2), 211223. 
Greengrass, M. (2002). Emotion and cognition work together in the brain. Americal Psychological Association, 33(6), 18.

Gupta, A., \& McDaniel, J. (2002). Creating competitive advantage by effectively managing knowledge: A farmework for knowledge management. Journal of Knowledge Management Practice, 3(2), 40-9.

Hamilton, B. A., \& Scandura, T. A. (2003). E-Mentoring: Implications for organizational learning and development in a wired world. Organizational Dynamics, 31(4), 388-402.

Hiltz, S. R., \& Goldman, R. (2005). What are asynchronous learning networks? In S. R. Hiltz \& R Goldman (Eds.). Learning together online: Research on asynchronous learning networks (pp. 319). Mahwah, NJ: Lawrence Erlbaum.

Honey, P. (2006). The Learning Styles Questionnaire: 80-item version. Maidenhead, UK: Peter Honey Publications.

Howard, P. (1995). The big five quickstart: An introduction to the five-factor model of personality for human resource professionals. Charlotte, NC: Centre for Applied Cognitive Studies.

Howard, P. J. (1998). An introduction to the five-factor model for personality for human resource professionals. Retrieved from www.centacs.com.

Jan, M. J. (2006). Neuroticism and introversion: A risky combination for disordered eating among a non-clinical sample of undergraduate women. Eat Behaviour Public Medicine, 7(1), 69-78.

Johnson, K. (1993). The Learning Organization. What Is It? Why Become One. Navran Associates' Newsletter.

Kassin, S. (2003). Psychology. Englewood Cliffs, USA: Prentice-Hall.

Kim, D. H. (1993). The link between individual and organizational learning. Sloan Management Review 35(1), 37-50.

Kolb, D. A. (1984). Experiential learning: Experience as the source of learning and development. Englewood Cliffs, USA: Prentice-Hall.

Lester, D. L. (2002). Aligning factors for successful organizational renewal. Leadership \& Orghanizational Development Journal, 23(1-2), 60-67.

Levinthal, D. A., \& March, J. G. (1993). The myopia of learning. Strategic Management Journal, 14(S2), 95-112.

Ludwig, G. A. (2011). A managerial perspective of dynamic capabilities in emerging markets: The case of the Russian steel industry. Journal of East European Management Studies, 16(3), 215-236.

Lynam, D. R.-L. (2005). Adolescent psychopathy and the big five: Results from two samples. Journal of Abnormal Child Psychology, 33, 431-443.

Matlin, M. (2009). Cognition. Hoboken, NJ: John Wiley \& Sons.

Matthews, G. D. (2003). Personality traits (2nd ed.). Cambridge: Cambridge University Press.

McCrae, R. (1992). An introduction to the five-factor model and its applications. Journal of Personality, 2, 174-214.

Mcdermott, M. (2005). Knowledge workers: You can gauge their effectiveness. Leadership Excellence 22 (10), 15-17.

McGlone, M. S. (2007). Forewarning and forearming stereotype-threatened students. Communication Education, 56, 119-133.

Merriam, S. B. (2002). Andragogy and selfdirected learning: Pillars of adult learning theory. New Directions for Adult and Continuing Education, 2001(89), 3-14.

Morgan, G. (1996). Images of Organization. 2nd ed. Thousand Oaks, CA: Sage Publications.

Motamedi, K. (2006). Seven Neurotic Styles of Management. Graziadio Business Review 9 (4)

Mumford, A. (1991). Individual and Organisational Learning. Industrial \& Commercial Training, 23(6).

Nonaka, I. A. (2001). Managing Industrial knowledge. London: Sage. 
Nonaka, I., \& Takeuchi, H. (1995). The Knowledge Creating Company. New York: Oxford University Press.

Pedler, M. B. (1997). The Learning Company: A strategy for sustainable development (2nd ed.). London: McGraw-Hill.

Popper, M. A. (2001). Organizational learning: mechanisms, culture, and feasibility. Management Learning 31(2), 181-196.

Reinhardt, W., Schmidt, B., Sloep, P., \& Drachsler, H. (2011). Knowledge worker roles and actions: Results of two empirical studies. Knowledge and Process Management, 18(3), 150-174.

Rheem, H. (1995). The Learning Organization. Harvard Business Review, 73(2), 10.

Robinson, M. D., Harmon, E. -J., \& Watkins, E. R. (2013). Handbook of cognition and emotion. New York, USA: The Guilford Press.

Russon, J. (2003). Human experience: Philosophy, neurosis, and the elements of everyday life. New York: State University of New York Press.

Ryan, R. M., \& Deci, E. L. (2000). Selfdetermination theory and the facilitation of intrinsic motivation, social development, and well-being. American Psychologist, 55(1), 68-78.

Schouwenburg, H. C. (1995). Personality and academic competence. Poster presented at the seventh meeting of the International Society for Study of Individual Differences. Warsaw, Poland.

Senge, P. (1990). The Fifth discipline: The art and practice of the learning organization. New York: Doubleday.

Shapiro, D. (1989). Psychotherapy of neurotic character. New York: Basic Books.

Spitzer, R. L., \& Williams, J. B. (1980). Diagnostic and statistical manual of mental disorders. American Psychiatric Association.

Sternberg, R. J. (2009). Cognitive psychology (6th ed.). Belmont, CA: Wadsworth Cengage Learning.
Suchman, L. (2000). Organizing Alignment: The case of bridge building. Organization, 7(2), 311-327.

Takano, A. E. A. (2007). Relationship between neuroticism personality trait and serotonin transporter binding. Biological Psychiatry, 62(6), 588-592.

Teece, D., \& Pisano, G. (1994). The dynamic capabilities of firms: An introduction. Industrial and Corporate Change, 3(3), 537-556.

Teece, D. J. (2007). Explicating dynamic capabilities: The nature and microfoundations of (sustainable) enterprise performance. Strategic Management Journal, 28(13), 13191350.

Thompson, E. (2008). Development and validation of an international english bigfive mini-markers. Personality and Individual Differences, 45(6), 542-548.

Valerie, I. S., London, M. (2006). Continuous learning in organizations, individual, group, and organizational perspectives. New York: Psychology Press.

Watkins, K., \& Marsick, V. J. (1993). Sculpting the learning organization: Lessons in the art and science of systematic change. San Francisco, CA: Jossey-Bass.

Watson, B. D. (2002). Rethinking organisational learning (Doctoral Dissertation). Melbourne: Faculty of Education, Education, The University of Melbourne.

Webster, M. (2000). Learning. In Encylopaedia of Britannica. Chicago: Encyclopedia Brittanica, Inc.

Zimmerman, B. J. (1990). Self-regulated learning and academic achievement: An overview. Educational Psychologist, 25(1), 3-17.

Zimmerman, B. J. (1995). Self-regulation involves more than metacognition: A social cognitive perspective. Educational Psychologist, 30(4), 217-221. 